\title{
Investigation of carbon monoxide in heavy traffic intersections of municipal districts
}

\author{
${ }^{I^{*}}$ M. Malakootian, and ${ }^{2}$ K. Yaghmaeian \\ ${ }^{I}$ Department.of Environmental Health, School of Public Health, Kerman University of Medical Sciences, Kerman, Iran \\ ${ }^{2}$ Department.of Environmental Health, School of Public Health, Semnan University of Medical Sciences, Semnan, Iran
}

\begin{abstract}
In this research, an investigation of carbon monoxide in heavy traffic intersections of Kerman municipal districts in 2003-2004 has been performed. Kerman City is located at the south-eastern part of Iran. Carbon monoxide in highly toxic for human health and natural ecosystems in metropolition districts especially due to high traffic and industrial activities. For this reason, it was decided to investigate and find out the high concentration of $\mathrm{CO}$ pollutants in heavy traffic intersections of Kerman City. In this regards 21 heavy traffic squares and intersections were selected and the concentration of $\mathrm{CO}$ were measured. In the middle of each month during the year, sampling and measurement were scheduled three times at daily times according 7-12 a.m.; 12-16 and 16-20 p.m. In each period, 12 samples of 5 minutes were collected and $\mathrm{CO}$ concentration for 1-hr was calculated. The results obtained indicate that the hourly mean concentrations were lower than WHO guidelines and also lower than measurements of 1989, which has already done. In spite of more cases and higher populations, natural gas distribution was the cause of decline in $\mathrm{CO}$ concentrations.
\end{abstract}

Key words: Carbon monoxide (CO), air pollution, traffic, municipal district, Kerman City

*Corresponding Author E-mail: MMalakoot@yahoo.com

\section{Introduction}

Air pollution has a history of thousand years, but it becomes human health and environmental problems by the beginning of industrial revolution. Traffic in metropolitan area is the leading cause of pollutants emission especially for CO and also NOx, VOCs, SOx and particulates (Harrop, 2002). CO is a colorless, odorless and tasteless gas, which is not easily detected by olfactory senses. It is a by-product of fossil fuel combustion. In central parts of cities where traffic jam occurs, high concentration of this pollutant will show up and problems of this gas are more serious (Colls, 2002; EPA, 2000; ALA, 2000 and WDNR, 2000). Discharged CO from motorized vehicles and other sources to air will have indirect effects on climate change and in addition adverse health effects on exposed humans (ALA 2000 and AGU, 1995). CO is not highly soluble in water, so it penetrates in lung and transfers into blood stream, combines with hemoglobin to produce $\mathrm{COHb}$. $\mathrm{CO}$ is prevented blood capacity in oxygen transfer to body tissues such as heart and brain. The reactivity of $\mathrm{CO}$ with hemoglobin is 240 folds greater than oxygen (Harrop, 2002 and WHO, 1999). In the presence of CO, oxygen falls to combine with hemoglobin. Effects of $\mathrm{COHb}$ in blood are associated to long half-life, which is nearly 5 hours (Guest, 1995). The effects of $\mathrm{CO}$ depend on concentration, exposure time, and health status of people, their age and activity. Long-term exposure to low concentrations of $\mathrm{CO}$ can have similar effects to short- term exposure with high concentrations. CO loading in blood reduces volume of blood distributed to body tissues. As a result, ability of healthy individuals is reduced for running, working, walking and other activities. The symptoms of exposure to $\mathrm{CO}$ start with headache, tiredness, dizziness, nausea, vomiting, and drowsiness and in very acute situation; unconsciousness and death will follow (Harrop, 2002). CO toxicity sings may be seen easily or not distinguished. Reason of this concern is similarity between toxicity symptoms caused by this gas and other health problems for human. This troubles including seasickness, cold, use of beyond limit of alcoholic drinks and natural nervous tensions is 
seen after spender day in seashore (fatigue, eye tiredness and other sunstroke effects). Many of these symptoms have distinguished by inadequate effects of $\mathrm{CO}$ accumulation in the environment. Each of sings or many of them may be divulging by other defects (WBSOA, 2003; EPA, 2003 and Akshay, 2003). Appearing this signs is changed for various individuals and or in different situations. Smokers, who that exposed with high concentration of smoke, alcohol users, individuals with chronic illnesses are more susceptible specially (WDNR, 2000). Generally fetus, childerens, elderly individuals, who that past record of heart and respiratory diseases, individuals that long-term exposure to this gas are more vulnerable against pollution of CO gas (WHO, 1999). At this basis in American National Standards of ambient air, 8-hr mean concentration and 1-hr mean concentration of $\mathrm{CO}$ gas should not be exceeded from 9 and $35 \mathrm{ppm}\left(10,40 \mathrm{mg} / \mathrm{m}^{3}\right)$ respectively (Heindsohn, et al., 1999). Concentration of this gas should not be exceeded of this limit once during year. Also in Iranian standard and WHO guidelines, 8-hr maximum concentration and 1 -hr maximum concentration of this gas in ambient air is 9 and $26 \mathrm{ppm}\left(10,30 \mathrm{mg} / \mathrm{m}^{3}\right)$ respectively (WHO, CEHA, 1998 and WHO, 1999). Citizens in different cases are exposed to various concentration of this gas. Various concentration of this gas is existence in ambient air of schools, universities, dwellings, streets, surrounding of industries and are affected humans in some ways. Locations, which are encountered with high concentration of this gas caused by full traffic, are intersections and squares of inside of cities (WDNR, 2000). Whereas first of all efforts for pollution control, is known of existence state of pollution levels, in order to investigate of important intersections and squares of Kerman City for this pollutant concentration in full traffic hours, comprehensive investigation was accomplished in 2003 - 2004. Also in this concern an investigation has been already done by the author and other colleagues on $\mathrm{CO}$ concentration in Kerman City air in 1998 (Malakootian, 1999). This survey was focused on the natural gas distribution in Kerman City and relative emission of one of the important air pollution sources which was incomplete combustion of liquid fuel in domestic, commercial and industrial sources inside and outside the city; it had brought some specific significance for urban planners.

\section{Materials and Methods}

The sampling plan was done according to the 21 Stations which are shown at the Kerman map (Ghiassedin, 1995) in the heavy traffic squares and intersections (Figure 1). In the middle of each month during 2003-2004, in one day 3 times sampling and measurement were scheduled at daily times: 7-12 a.m.; 1216 and 16-20 p.m. and in each period, 12 samples within 5 minutes were collected and $\mathrm{CO}$ concentration for $1-\mathrm{hr}$ mean was calculated. The applied analyzer was "KaneMag SG91C CO single gas" which was calibrated periodically during sampling (Harrop, 2002).

\section{Results}

To find out the variation amount of $\mathrm{CO}$ in each Station at different times of the day, hourly concentration of $\mathrm{CO}$ was averaged for the timing of 7-20 hours, of the measuring daily and also 8-hour mean was also calculated for comparing with WHO guidelines and Iranian standards. The results of measurements and calculations are summarized in Table 1 for all 21 Stations. This data have arranged as maximum to minimum concentration of carbon monoxide in Stations. Comparison of $\mathrm{CO}$ in heavy traffic squares and intersections are shown in Figure2.

Table 1 means hourly concentration of $\mathrm{CO}$ in heavy traffic squares and intersections of Kerman City in various hours of day (Values are as ppm).

\section{Discussion and Conclusion}

The results of analysis indicate that in none of the Stations and the mean concentration were not exceeded from WHO guidelines and Iranian national standards. The maximum concentration of $\mathrm{CO}$ sometimes was reached $14 \mathrm{ppm}$ that still is half of WHO hourly guideline. There have been similar researches in 1989 that the range of $\mathrm{CO}$ concentrations for 8- hours' average was between 3-7 ppm. To compare with 8 hours average of year 20032004 , which was $1.3-8.3 \mathrm{ppm}$, it is concluded that the $\mathrm{CO}$ have been declined from year 1989. This happened although numbers of motorized vehicles have been increased from 106672 in 1989 to 162307 in 2004 . In spite of 


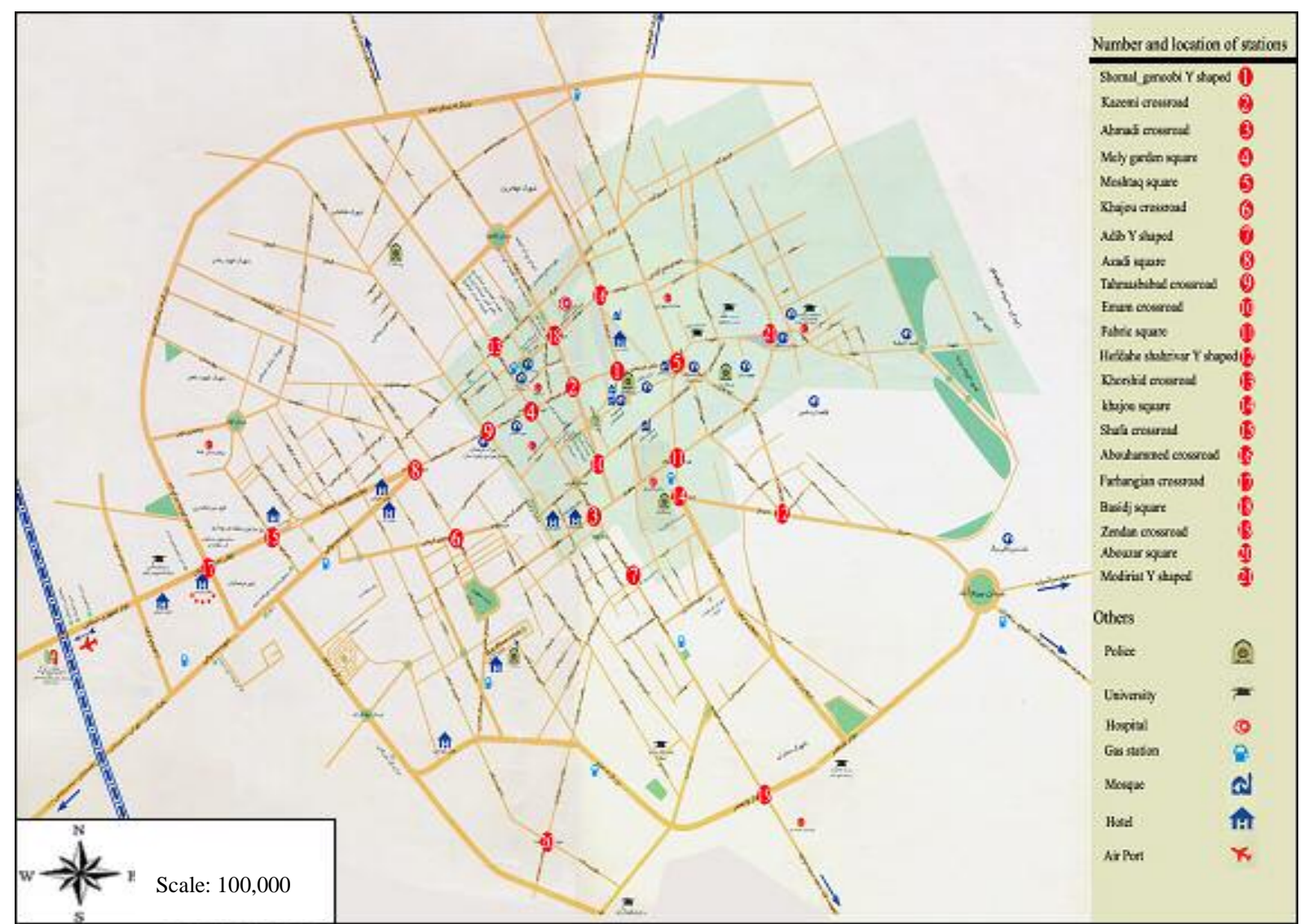

Figure 1: Location and number of sampling Stations on the map of Kerman City in Iran

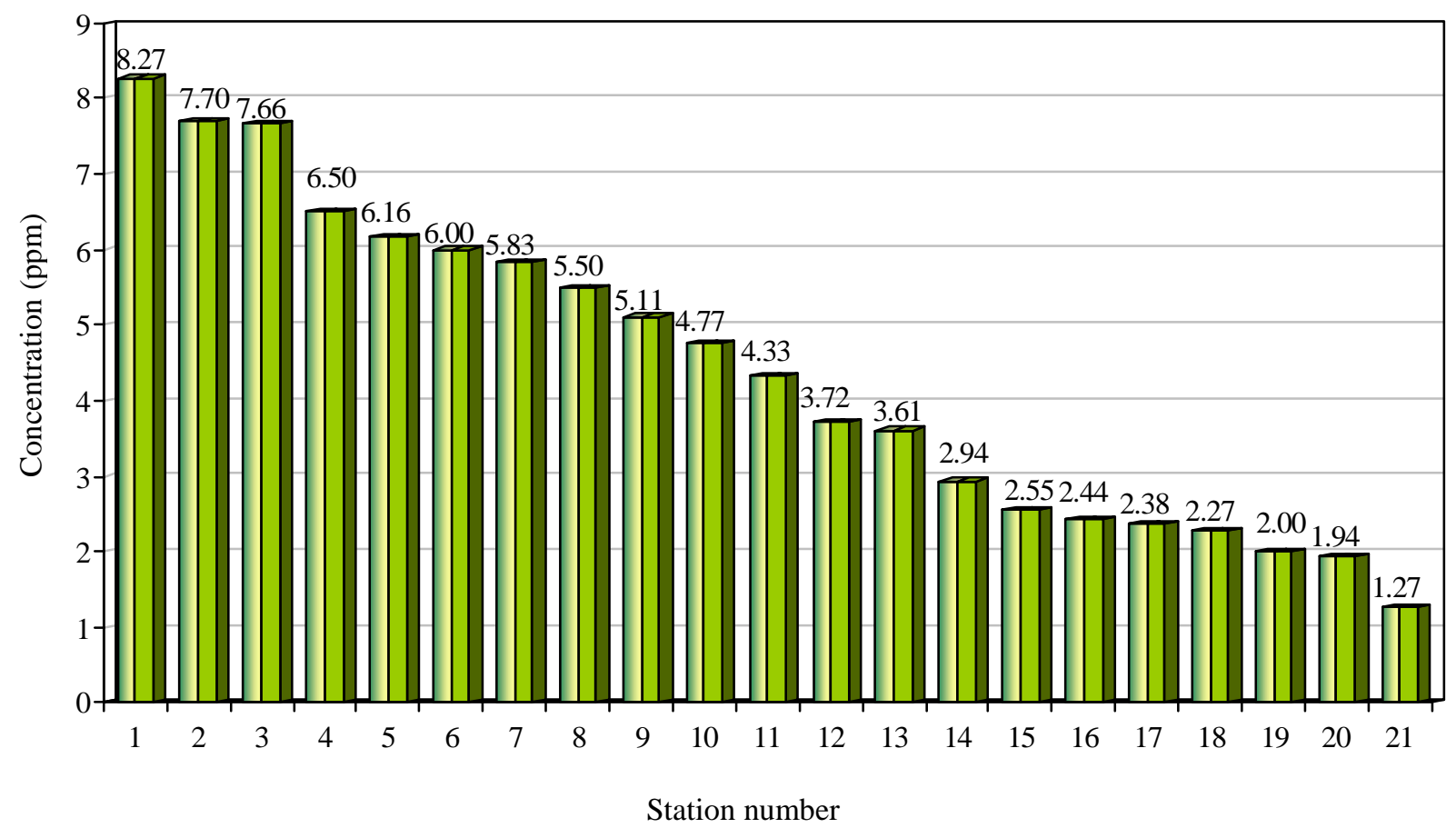

Figure 2: Comparison of 1-hr concentration (7-20 hours) of $\mathrm{CO}$ in heavy traffic squares and intersections of Kerman City in 2003-2004 
increasing car density, the natural gas distribution development could be the main reason for $\mathrm{CO}$ concentration decreases.

Comparing Stations with each other's Stations 1, 2, 3, 4 and 5 with 8.3, 7.7, 7.7, 6.5 and $6.2 \mathrm{ppm}$ respectively are among highest concentration and Station No. 21 with $1.3 \mathrm{ppm}$ included the lowest concentration. Although $\mathrm{CO}$ concentration in Kerman City definitely lower than WHO guidelines and Iranian national standards, but it is not because of reducing of motorized vehicles. Attention to motorized vehicles and finally high percent of traffic consequences and air pollution due to increasing trend of population and number of thermal inversion in Kerman City is so important. With attention to this survey and the other one in year 1989 and also regarding the ecological conditions of Kerman City, some recommendations are presented as follows;

- Using of public transport and starting underground train survey as long-term program.

- Extending of streets and reforming the intersections by using of approval plans.

Table 1: Mean hourly concentration of CO in heavy traffic squares and intersections of

Kerman City in various hours of day (values are as ppm)

\begin{tabular}{|c|c|c|c|c|c|c|c|c|c|c|c|c|}
\hline \multirow{2}{*}{ 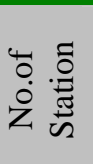 } & \multirow{2}{*}{$\begin{array}{l}\text { Location of sampling } \\
\text { Station }\end{array}$} & \multicolumn{3}{|c|}{ Hour (7-12) } & \multicolumn{3}{|c|}{ Hour (12-16) } & \multicolumn{3}{|c|}{ Hour (16-20) } & \multirow{2}{*}{$\begin{array}{l}\text { 1-hr } \\
\text { mean }\end{array}$} & \multirow{2}{*}{$\begin{array}{l}\text { Standard } \\
\text { deviation }\end{array}$} \\
\hline & & $\min$ & $\max$ & mean & $\min$ & $\max$ & mean & $\min$ & $\max$ & mean & & \\
\hline 1 & $\begin{array}{l}\text { North-south Y } \\
\text { shaped }\end{array}$ & 5 & 10 & 8.66 & 7 & 9 & 8.00 & 4 & 11 & 8.16 & 8.27 & 3.20 \\
\hline 2 & Kazemi crossroad & 6 & 12 & 8.30 & 7 & 11 & 8.00 & 5 & 10 & 7.00 & 7.70 & 4.40 \\
\hline 3 & Ahmadi crossroad & 4 & 11 & 8.16 & 7 & 10 & 7.83 & 3 & 12 & 7.00 & 7.66 & 8.56 \\
\hline 4 & Melli Bagh square & 7 & 14 & 11.00 & 2 & 13 & 7.33 & 0 & 2 & 1.16 & 6.50 & 25.36 \\
\hline 5 & Moshtaq square & 5 & 8 & 6.33 & 3 & 10 & 5.66 & 4 & 8 & 6.50 & 6.16 & 2.70 \\
\hline 6 & Khajou crossroad & 4 & 13 & 7.00 & 2 & 8 & 4.66 & 3 & 12 & 6.33 & 6.00 & 8.22 \\
\hline 7 & Adibb Y shaped & 3 & 8 & 5.33 & 4 & 7 & 5.33 & 3 & 11 & 6.83 & 5.83 & 3.98 \\
\hline 8 & Azadi square & 4 & 13 & 7.83 & 2 & 6 & 4.16 & 1 & 11 & 4.50 & 5.50 & 10.70 \\
\hline 9 & $\begin{array}{l}\text { Tahmasbabad } \\
\text { crossroad }\end{array}$ & 2 & 8 & 6.00 & 2 & 8 & 4.66 & 2 & 9 & 4.66 & 5.11 & 5.04 \\
\hline 10 & Emam crossroad & 2 & 7 & 4.16 & 4 & 5 & 4.83 & 4 & 7 & 5.33 & 4.77 & 1.84 \\
\hline 11 & Fabric square & 2 & 4 & 3.00 & 3 & 8 & 5.66 & 2 & 8 & 4.33 & 4.33 & 4.56 \\
\hline 12 & $\begin{array}{l}\text { Hefdahe shahrivar } \\
\text { Y shaped }\end{array}$ & 3 & 9 & 5.66 & 2 & 4 & 3.16 & 0 & 6 & 2.33 & 3.72 & 5.42 \\
\hline 13 & Khorshid crossroad & 2 & 10 & 4.50 & 2 & 4 & 3.16 & 2 & 5 & 3.16 & 3.61 & 3.35 \\
\hline 14 & Khajou square & 2 & 4 & 3.33 & 3 & 6 & 3.83 & 0 & 3 & 1.66 & 2.94 & 1.94 \\
\hline 15 & Shafa crossroad & 0 & 3 & 1.83 & 0 & 7 & 2.66 & 1 & 7 & 3.16 & 2.55 & 3.80 \\
\hline 16 & $\begin{array}{l}\text { Abouhammed } \\
\text { crossroad }\end{array}$ & 2 & 5 & 2.83 & 1 & 5 & 2.33 & 1 & 5 & 2.16 & 2.44 & 1.90 \\
\hline 17 & $\begin{array}{l}\text { Farhangian } \\
\text { crossoad }\end{array}$ & 0 & 7 & 2.66 & 0 & 5 & 2.33 & 1 & 5 & 2.16 & 2.38 & 3.80 \\
\hline 18 & Basidj square & 2 & 4 & 3.16 & 1 & 3 & 2.00 & 1 & 2 & 1.66 & 2.27 & 1.04 \\
\hline 19 & Zendan crossroad & 0 & 4 & 2.00 & 2 & 4 & 3.00 & 0 & 4 & 1.00 & 2.00 & 2.10 \\
\hline 20 & Abouzar square & 1 & 4 & 2.00 & 1 & 3 & 1.50 & 1 & 7 & 2.33 & 1.94 & 2.45 \\
\hline 21 & Modiriat Y shaped & 1 & 3 & 1.33 & 1 & 2 & 1.33 & 1 & 2 & 1.16 & 1.27 & 0.31 \\
\hline
\end{tabular}


- Staying of traffic policemen at specific points with lower concentration of $\mathrm{CO}$ in interactions Nos. 1 to 5.

- Constructing of overpass and facility like this based on survey results for preventing of traffic problems in intersections No. 1 to 5.

- Gas burning the motorized vehicles especially public transportations.

- Planning for sending out of the old aged vehicles from city transportation navigation (public and private) and permanent controlling of motor tune up.

- Per capita of parks and green lands in Kerman City is about $9.6 \mathrm{~m}^{2}$, that in comparing with $30 \mathrm{~m}^{2}$ of UN standard and $12 \mathrm{~m}^{2}$ of recommended by Iranian ministry of housing and city management is very low.

- Public education in different levels for proliferation of general knowledge.

- Constructing of pollutant monitoring system by using permanent and mobile Station for sampling and measurement of principal pollutant of the air in the city.

\section{References:}

Akshay S., Human health effects of CO. J. Bums and surgical wound Care, 41:1-6, 2003

American Geophysical Union, Decline in atmospheric CO raises questions about its cause. J. Earth in space 8 (3): 7-12,1995

American Lung Association (ALA), Carbon monoxide and the environment. U.S.A., 2000 available at: http://www.lunguas.org/air/Carbon

Bahramsoltani K., The role of municipal space architectural in new periods of citizen. Journal of Sabzineh, 5:11-15,2002

Colls J., Air Pollution. $2^{\text {th. }}$ Ed., Spon Press, London, England, 2002

Ghiassedin M., Investigation of Kerman Csity air pollution. Environmental protection Bureau of Kerman, Kerman, Iran, 1995

Guest H. B., Carbon monoxide. Hamel Volunteer Fire Dept., U.S.A., 1995

Harrop D. O., Air quality assessment and management: A practical guide. Spon press, London, England, 2002
Heindsohn R. J. and R. L. Kabel, Sources and control of air pollution, prentice-Hall Inc., U.S.A., 1999

Malakootian M., M. Shariat and M. Ghiassedin, Kerman's air pollution situation. Iranian J. of public health, 28:1-4,1999

USEPA, Amebient air pollutants emission sources. EPA, U.S.A., 2003

available at:

http://www.epa.gov/air/urbanait/co/hlthl.html

USEPA, Health and environmental impacts of CO. EPA, U.S.A., 2003.

available at:

http://www.epa.gov/air/urbanair/co/hlth1.html

US. EPA, How Carbon monoxide affects the way we live and breathe. EPA, U.S.A., 2000 available at: http://www.epa.gov/air/urbanair/co/hlth1.html

WBSOA, Carbon monoxide the silent killer a board your boat. Washington state Boating Safety Officers Association, Washington, U.S.A., 2003

WDNR, Carbon monoxide sources and health affects. Wisconsin Dept. of Natural Resources, U.S.A., 2000

available at: http://www.dnr.state.wi.us

WHO, Environmental health Criteria-No. 213Carbon monoxide, WHO, Geneva, 1999

WHO, CEHA, Air quality standards, Netherlands, 24: 6-7, 1998 
